\title{
Altruism as an Explanation for Human Consanguinity
}

\author{
Srdjan Denic ${ }^{a}$ Mukesh M. Agarwal ${ }^{b}$ \\ ${ }^{a}$ College of Medicine and Health Sciences, United Arab Emirates University, Al Ain, UAE; ${ }^{b}$ California University of \\ Science and Medicine, San Bernardino, CA, USA
}

\section{Keywords}

Mate selection · Human altruism · Human inbreeding •

Sociobiological principles of behavior - Public health

Community genetics

\begin{abstract}
Background: Human inbreeding is a sociobiological puzzle. Despite widespread knowledge of its potential for genetic disorders, human consanguinity remains surprisingly common. The current reasons explaining its continued persistence in today's modern world have major shortcomings. Summary: We propose that the Neolithic Agrarian revolution modified the structure of populations. It increased competition for the limited resources in which a larger group had better chances of survival. As a result, small, drifting, socially open bands of hunter-gatherers were transformed into bigger, less mobile, and more powerful kinship groups (tribes). In this transformation, a central role was played by human trust - an aspect of human altruism which is a universal sociobiological principle of behavior. Altruism (and trust) is an essential premise of social contracts such as economic cooperation, marriage arrangement, and creation of alliances between people. In kinship groups, human trust is limited to
\end{abstract}

kin, so tribes remain small, economically poor, and consanguineous due to lack of nonkin mates. The expanding of trust from kin to that of nonbiological relatives increases the size of human groups, fosters economic wealth, and decreases the rate of consanguinity. Key Messages: The lack of nonkin altruism leads to: (a) poverty (due to poor economic cooperation with nonkin), (b) maintaining small group size, and (c) inbreeding.

(c) 2021 The Author(s) Published by S. Karger AG, Basel

\section{Introduction}

Consanguineous marriages are a sociobiological puzzle. Despite the high potential for genetic disorders among children, such marriages are remarkably common, with an estimated $10 \%$ of world population being of consanguineous parentage $[1,2]$. Consanguineous marriages occur in 2 main settings: (i) geographical isolates (e.g., small distant islands, and remote mountainous villages) and (ii) ideological isolates. The latter often consist of kin groups (tribes), wherein marriages are arranged within and forbidden between groups, a prominent pattern in large societies of North Africa, the Middle East, and South Asia. 
Small religious groups and small tribal (often geographically isolated) societies, and some ethnic groups within large Western societies are also examples of ideological isolates [3]. The distribution of human consanguinity by country is available at consang.net.

In the past 6 decades, sociobiology (i.e., evolutionary sociology, evolutionary psychology, and evolutionary anthropology), which applies evolution by natural selection to studies of human behavior, has provided novel insights into relationships between human behavior and biology [4-6]. In this article, we invoke sociobiological principles of human behavior to explain consanguineous marriage in diverse societies. In the first part, we discuss current explanations for close-kin marriage, and in the second, we offer a novel model for tribal consanguinity, centered on the importance of altruism for the survival of human groups.

\section{Some Limitations of Current Models of Consanguinity}

There are many explanations for close-kin marriages. In anthropological literature of the 20th century, closekin and nonkin marriages were explained by the marriage model of Claude Levi Strauss. He hypothesized that incest taboo "pushes" an individual/family to "marry-out" and exchange of women occurs as "gifts" between 2 families or groups [7]. This marriage model evolved over time and became more complex; subsequently, its popularity diminished. Nonetheless, it points to the importance of human cooperation and reciprocal altruism (gift exchange) and socioeconomic factors (woman as ultimate "gift") in the arrangement of marriages.

The sociomedical literature of 20th century provides another 2 explanations for consanguineous marriages. In geographical isolates, unions between close kin are attributable to the scarcity of marriageable individuals. In the tribal settings, where most inbreeding occurs, consanguinity is connected with tradition, culture, and socioeconomic deprivation $[1,8-10]$. The first criticism of these models of consanguinity is that they contradict Occam's principle that a simple explanation of a phenomenon is preferable to a complex one. Further, the "tradition" and "culture" have a little instructive value because they are the similar, overlapping concepts that recognize the existence of this marital behavior but do not explain it. Instead, they appear circuitous (if consanguineous marriages are present in a society, they are a part of its "tradition" and "culture" and vice versa) and at least imply that the practice continues because of "social inertia." The role of socioeconomic deprivation (e.g., poverty, insecurity, and the lack of education) as a plausible explanation for human inbreeding also needs to be scrutinized.

The socioeconomic model of consanguinity originated from 20th-century observations of the prominence of close-kin marriages in relatively underdeveloped parts of the world. It has thus been claimed that intra-family marriages (a) alleviate poverty by avoiding dispersal of family wealth to nonkin and (b) increase physical security by offering better protection to related family members [ 1 , $8-10]$. Such unions are also easier to organize as the parents of a couple are closely related (often siblings) and the characteristics (fitness traits) of kin mates are better known by both families than those of nonkin mates are [3]. It is also argued that kin marriages are typically arranged among the poor and uneducated, who are ignorant of the biological consequences of inbreeding $[8,10]$. Moreover, poorer families in tribal societies are more likely to be consanguineous than wealthier families are, further validating the socioeconomic explanation for human inbreeding [1]. The economic model can be criticized insofar as some underdeveloped populations exhibit few consanguineous marriages. Admittedly, to the best of our knowledge, marital behavior in such populations (e.g., rural Russia and Bosnia and Herzegovina) has not been studied. Conversely, many tribal societies continue to practice consanguinity even after becoming rich, socially secure, and better educated [11]. Similarly, in many bygone societies, consanguinity was more prevalent among the wealthier strata [12].

Another line of criticism is that the socioeconomic model of consanguinity concentrates on the genetic harm of inbreeding, while ignoring observations contrary to its central tenet of inbreeding depression. One such observation is the ubiquity of inbreeding in animals and plants, and the emergence of inbreeding tolerance and inbreeding preference by natural selection found in some animal studies $[13,14]$. In humans, this is suggested by the finding that many medical students (in consanguineous populations), despite being aware of the biological effects of inbreeding, have no marital preference between nonkin and first cousins (tolerance), and some clearly prefer to marry first cousins [15]. Such studies also raise doubts about the importance of education in socioeconomic models of consanguinity.

Higher consanguinity rates among the poorer strata of society are better explained by the lack of marriageable mates. In general, women prefer richer men (marry upward), whereas men care much less about a woman's sta- 
tus, and some men marry $>1$ woman from the pool of marriageable mates $[15,16]$. Both marital preferences decrease the number of available mates for the poorest men, who, facing difficulty in finding a mate, may seek to marry close kin. Similarly, "better preservation of family wealth" is not acknowledged in the literature as a means of increasing reproductive success in consanguineous families. Historically, more children from wealthy families than those from poor families have survived into adulthood [17]. This could offset inbreeding depression in relatively richer close-kin families. Likewise, "better protection of families" is consistent with Hamilton's theory of kin altruism; that is, altruism increases inclusive fitness in consanguineous families. In other words, "better protection of families" could improve reproductive success under certain conditions (with asymmetry of relative costs and benefits), thereby compensating for biological losses due to inbreeding [18]. In short, the socioeconomic model of close kin and reciprocal marriages has overlapping characteristics but both ignore many aspects of human behavior that might increase reproductive fitness.

\section{Sociobiological Model of Human Consanguinity}

\section{Model Summary}

We posit that close-kin unions maximize relative fitness in small human isolates characterized by the lack of marriageable individuals. The dearth of eligible mates is inversely related to the population of the isolate. Such communities may be created by either (a) geographical barriers or (b) ideological obstacles. In isolates, the reproductive costs of remaining unmarried and without progeny or breaking the isolation barrier are higher than those of marrying close kin. Consequently, union with close kin may increase relative fitness in human reproductive isolates. As most human inbreeding occurs in tribal societies, the model further elucidates the development and maintenance of ideological isolation in populations.

\section{Model Description}

Selection of Spouse: Avoidance of Kin and Importance of Parents

In traditional societies, reproduction occurs primarily within marriage. Per mate selection theory, the choice of spouse is governed by the predisposition to maximize fitness $[19,20]$. Mate selection requires an assessment of the costs and benefits of potential partners as estimated from their biological and psychosocial characteristics, for ex- ample, age, health, physical and psychological traits, social standing and material wealth, and individual and family reputation. In different environments, the various criteria for mate selection may affect the number, quality, and odds of survival of offspring differently; hence, their value may vary between societies. Additional factors, such as time lost in mate seeking and the cost of courtship and marriage, may affect mate selection $[16,21,22]$. While close biological relatives are potential mates, they are of low quality because of the decreased relative fitness of the offspring. Humans (and animals) have evolved to avoid inbreeding instinctively. In actually selecting a close biological relative for a spouse, this instinct operates in combination with learned, socially defined norms of mate selection to produce an incest taboo $[3,23,24]$; indeed, inbreeding avoidance is regarded as a universal sociobiological principle of behavior $[4,5]$. Furthermore, women are the choosier sex in mate selection because the cost of any failures is greater owing to their higher investment in each offspring (pregnancy and nursing). Consequently, they are more averse to inbreeding and the increased odds of child loss $[15,25,26]$.

Mate selection is always a family affair; however, marriages differ in terms of parental input on mate selection $[22,27]$. As parents and children share half of their genes, mate selection affects the relative fitness of both offspring and parents, which explains the parental desire to marry and support their child and the new family. Conversely, half of each parent genome differs from the child's, helping to explain parent-child disagreement in mate selection $[26,28,29]$. Unlike traditional societies, much family support in developed countries is undertaken by social institutions that make families less dependent on each other for survival. Nonetheless, the availability of a marriageable partner is a sine qua non of human reproduction. Therefore, the shortage of mates literally creates an existential crisis as it could result in total loss of fitness.

\section{Reproductive Strategies: Selection of a Spouse When} Mates Are in Short Supply

In small human isolates, the availability of marriageable individuals (reproductively compatible) is directly related to the size of group. In any such group, the nonmarriageable population comprises the already married, those reproductively incapable (too young or too old), members of the same sex, and the physically and mentally incapacitated. The shortage can be further exacerbated by polygyny and the less prevalent polyandry, both of which deplete the pool of potential mates. If the number of marriageable individuals is limited, what are the 
reproductive alternatives to the all-powerful human drive to procreate and maximize relative fitness? There are 3 potential options: (i) finding a mate outside the isolate, (ii) remaining unmarried and childless, and (iii) marrying a close biological relative.

(i) Marrying nonkin (outbreeding). In geographical isolates, a numerical shortage of marriageable nonkin can be overcome by selecting a mate from outside the isolate. This behavior is analogous to animal dispersal to avoid inbreeding [14]. Humans in geographical isolates, however, face difficult obstacles. The inhabitants, often located in mountainous villages or small remote islands, are usually poor and can rarely afford the cost of crossing geographical barriers. Poverty also decreases the odds of attracting a "good value" mate from the outside, particularly for men [16, 21]. Moreover, as the reputation of the individual and family is one of the most important criteria for social interaction and mate selection, it may be difficult to assess potential mates from a distance $[15,16$, 30]. Therefore, the high cost and the low chance of success make this mate selection strategy an unfavorable one.

By contrast, in large tribal societies, many marriageable individuals are present, yet marriages outside the kinship group are forbidden and usually self-avoided [8, $10,31]$. The social stigma against such unions is due to the mistrust of families in other tribal groups (see below). The cost of breaking social barriers is high because it often results in forced divorce, loss of family support, inability to remarry, and susceptibility to be punished with death $[3,10]$. By trying to circumvent social marital norms, an individual risks total loss of fitness, which makes mating outside the kinship group an uncommon option.

In Eurasia, bride kidnaping is often used to overcome geographic, social, and economic barriers that separate mates of marriageable age [32]. This mating strategy can trigger a war of revenge between groups, potentially resulting in an unintended loss of fitness. While this mating strategy results in outbreeding, it is risky, geographically confined, and officially outlawed.

(ii) Staying unmarried and childless (nonbreeding). The human drive to procreate - behavior that leads to production and support of children and grandchildren is exceptionally strong. Staying unmarried and childless results in a total loss of fitness. However, being childless can be ameliorated by supporting and improving the survival odds of close kin such as nephews and nieces. Such altruism increases the number of an unmarried person's genes, identical by common descent, that are propagated to the next generation by kin $[33,34]$. Gains through inclusive fitness are difficult to quantify in humans, but in general, staying unmarried and forfeiting 1 child $(R=0.5)$ necessitate that such a person ensures the survival of 8 nephews (or nieces) to attain equivalent fitness $(R=$ $0.0625 \times 8)-$ a murky and unpromising reproductive strategy.

(iii) Marrying close kin (inbreeding). In close-kin unions, inbreeding depression is proportional to the coefficient of inbreeding and is medically apparent from easily observed or measured signs such as physical malformations, congenital deafness, intellectual impairment, and changes in survival. The consequences of deleterious genes with minimal effect are often missed [35]. The likelihood of serious effects from inbreeding is generally overestimated by the public, a phenomenon called consanguinity illusion type I [36]. In comparative studies of inbred and outbred families, the actual numbers of affected descendants vary - depending on how and what medical conditions are studied - but their ratios remain constant and are proportional to $F$ [3]. In close-kin families with $R>0.25$ (incestuous union), around $50 \%$ of offspring are affected, that is, die early or are unable to reproduce [3]. In consanguineously marrying societies, however, there are inbreeding clusters at the lower risk end of the spectrum with a substantial majority of unions having $R \leq 0.125$ and never exceeding 0.25 . The most common marriage is between first cousins $(R=0.125)$, which produces two to three times more offspring affected by inbreeding in comparison with noncousin unions [3]. The communication of (relative) risk in terms of a frequentist formulation is often misleading and is more informative when performed using absolute numbers [37]. Thus, in studies of significant effects of inbreeding, 2 in 100 offspring ( 1 in 50) are affected in noncousin families on average, when compared with 5 in 100 offspring (1 in 20) in first-cousin families [38]. Expressed differently, in a large sample, 95 in 100 offspring of first-cousin families would avoid being grossly affected by inbreeding as against 98 in 100 in noncousin families, suggesting that the 2 groups are not so dissimilar. This perspective on the effects of consanguinity suggests that it is much less detrimental than commonly believed and may reduce people's aversion to selecting a spouse among close kin.

\section{Human Altruism and Population Structure}

Living in a group furnishes humans and animals with benefits such as better protection and additional means of locating food. It relies on an inherited predisposition for the members of a species to sacrifice their own wellbeing for that of others (altruism). The extent of human altruism, however, varies among individuals and is influ- 
enced by personal and shared experiences, learning, and culture $[5,39]$. As super-social animals, humans live in groups of different sizes. Much human inbreeding takes place in relatively small (tribal) groups wherein a large part of humanity lives even today [2]. In fact, life in kinship groups (tribalism) is inseparable from human inbreeding. Understanding human inbreeding thus requires a comprehensive understanding of the relationships between population structure, altruism, and reproduction.

\section{Altruism and Social Contract}

Self-sacrifice for the benefit of others has many aspects: kin and nonkin altruism, direct and indirect reciprocal altruism, strong reciprocal altruism, cooperation, reputation, and trust [40-43]. Altruism can be equated with human cooperation (social contract). In short, by working together, people create economic wealth and build social institutions. Cooperation requires an initial investment (of time, money, or other resources) but can create value far exceeding that of the original principal. Today, much socioeconomic development results from people cooperating for their own benefit and for the common good of others [39].

Cooperation is, however, precarious because a participant could abrogate the social contract. The defection of 1 contributor from a deal results in losses to the other parties. Thus, entering into a social contract with others is always risky and involves a willingness to imperil one's own well-being (fitness) for the benefit (fitness) of others. Altruism makes social contracts possible. Conversely, lack of altruism leads to defaults in social contracts, losses to individuals, and less wealth for the society in which people live and work. The prevention of such losses is essential for one's well-being and can be accomplished by avoiding cooperation with "bad actors" [39]. Intuitively, we avoid past defectors and known cheaters and prefer to collaborate with trustworthy individuals. Those whom we can trust most are, in general, our close biological relatives.

\section{Kin Altruism and Inclusive Fitness}

In a very crude sense, we are all kin. In a family tree, kinship is defined by $R$ and is halved in each generation, so that after multiple generations $R \rightarrow 0$. Hamilton's rule for kin altruism $(c<b \times R)$ predicts that the willingness to incur the cost of self-sacrifice $(c)$ is greater for close kin than it is for distant kin or nonkin. Through common descent, kin share a fraction $(R)$ of their genes; hence, an individual who helps kin survive facilitates the propaga-

Human Inbreeding tion of their own alleles to the next generation. The benefit to the recipient of this altruism is described by $(b)$. As closer kin share more genes, more benefit is derived from helping them than that from helping distant kin. The theory of kin altruism validates the accepted truism that we tend to help close kin more than distant-kin and nonkin. In social contracts, kin are universally considered more trustworthy than nonkin. In the event of a default from social contracts by kin, loss to 1 party necessarily affects the kin defector in an amount proportional to their common genetic heritage $(R)$, thereby discouraging dishonesty. Likewise, in successful social contracts among kin, gains by 1 side also accrue to the other (kin cooperator) in an amount proportional to $R$, thus encouraging cooperation. Such fitness is inclusive, encourages cooperation, discourages defection, and forms the basis of human nepotism - the preferred selection of kin over nonkin for partnership in a social contract. Admittedly, altruism is founded on the principle of selfishness and the view that genes are the primary objects of natural selection $[33,34$, 44].

Nonkin Altruism: Reciprocity, Reputation, and Trust

More often than not, we help nonkin. Consider the extensive favors we provide friends, colleagues, and biologically unrelated spouses. Because of the inconsistency between costly self-sacrifice $(c)$ and low $R(\rightarrow 0)$, the theory of kin altruism is not easy to validate. This concern is addressed by the reciprocity principle: we help those from whom we expect a quid pro quo $[41,43]$. The ability to distinguish nonkin who will reciprocate from those who will default on social contracts is essential for one's wellbeing and survival. The ability to recognize trustworthy people has been posited as the main driving force in the evolution of human cognitive abilities (memory, intelligence, and language), which are located in the neocortex [45].

Human trust and reputation are inter-related. We trust reputable individuals and vice versa. Reputation and trust are 2 sides of the same coin. Reputation is determined by behavior in past social contracts and can be viewed as a "score card" of defections and cooperation by an individual in their past dealings with others. Every person builds his/her own reputation in the minds of others, an "image" that is created from direct personal experience or information from others transmitted through gossip, conversation, or review of a resume or letter of recommendation [46]. Admittedly, the reputation of the same individual may vary among others in light of personal experiences and unreliable transmission of information. 
We are more willing to sacrifice for trustworthy individuals than we are for the less trustworthy. If the reputation/ trust of a person is $R u$, then the analog to Hamilton's rule for nonkin altruism is $c<b \times R u$.

Existing theory defines kinship with $R$ (the proportion of genes shared by common descent), but there is no known single gene or group of genes for altruism. Reports linking oxytocin with prosocial behavior have produced tentative results at best [47]. Kin recognition is best viewed as an emerging trait acquired by learning; the strength of kinship (closeness) is directly proportional to the physical proximity of individuals and its duration and is especially strong in early age $[23,48,49]$. The evolutionary origin of kinship and altruistic behavior is linked to the biologically defined need for physical proximity between mother and offspring.

Trust, which is a mirror image of another person's reputation, is likewise acquired through learning - the sum total of positive and negative outcomes in past social contracts. As kinship and trust are both products of cognition, they may have a common origin. We can state that $R u=R$ at the time of our birth, but that $R u$ diverges thereafter. Indeed, we may sacrifice more for reputable nonkin than we may for discredited close kin. Thus, establishing the rule $c<b \times R u$ for altruism creates a more inclusive description of human self-sacrifice for the benefit of others as it overcomes the artificial division between kin and nonkin altruism $[42,50,51]$.

Humans also acquire trust of others through various other means. In experiments, individuals consistently helped strangers with the same family name more than they did strangers with a different one [52]. Tribal allegiance is defined by family name and is a signal of kinship in such societies. In human relations, the head of a family sometimes vouches for close kin, enabling a social contract and effectively confirming their trustworthiness. Kinship and trust can also be signaled by a dress code (e.g., national dress, military uniform, or white coat), religious affiliation, and spoken language and dialect [53, 54].

\section{Relative Benefits of Kin and Nonkin Cooperation}

People instinctively prefer to cooperate with the most trustworthy individuals regardless of whether kin or nonkin. However, cooperation with nonkin is potentially more productive than that with kin for 2 reasons. First, in most societies, the population of nonkin is larger than that of kin. Hence, a greater number of potential social contracts can be arranged with nonkin than what can be arranged with kin. Second, nonkin social contracts are potentially more productive because nonkin are likely to have more diverse skills, unique knowledge, and resources that could be used more fruitfully in cooperation. Furthermore, in nonkin social contracts, the multiplier effect of their larger numbers and higher productivity contributes to bigger, more rapid socioeconomic growth. However, the lower reliability of nonkin deters social contracts between biologically unrelated individuals and constrains individual and social development [39]. Human trust and socioeconomic growth are positively correlated [55]. In 1 international study, a correlation was found between the GDP of countries and the level of trust expressed by their nationals [56].

In a population characterized by a low level of trust due to a high number of social contract defectors, one way of preserving individual well-being is to restrict or completely avoid social contracts with nonkin and to limit cooperation to more trustworthy kin. Such behavior is an extreme form of nepotism but is rational (adaptive) if it increases relative fitness by precluding loss in dealings with untrustworthy nonkin [39].

Importance of Kin Recognition and the "Circle of Trust"

Kin recognition is important for 2 reasons: identifying whom not to marry (inbreeding avoidance) and whom to cooperate with (trust). Relative to most animals, smell plays only a small role in signaling biological closeness and regulating inbreeding in humans [57]. Humans rely instead on cognitive faculties (memory, intelligence, and language) to recognize kin [58]. In primates, the size of the neocortex, where cognitive abilities are located, is correlated with the size of social groups; humans have the largest neocortex and unsurprisingly live in the largest social groups $[45,59,60]$.

The number of people we can know well enough to make reasonably accurate predictions about future behavior has been shown to be limited to between 100 and 250 , mean $n=150$. This is known as Dunbar's number and is a proxy for the capacity of human memory to store identifying characteristics of biological kin as well as kin by marriage, friends, and colleagues $[59,60]$. The individuals we know best are selectively remembered because they can be trusted; they are the "human capital" of each person, which, through social contracts and mate selection, are used to maximize our well-being and ultimately reproductive success.

"Human capital" is important for the well-being of the individual and is continuously updated. In addition to reputation, the question of whom one selects to know well depends on a person's age as well as characteristics such 
Table 1. Human group size, kin in the "circle of trust," and inbreeding ${ }^{a}$

\begin{tabular}{|c|c|c|c|c|c|c|}
\hline Small & $\begin{array}{l}\text { Hunter-gatherers } \\
\text { Bands/villages }\end{array}$ & $1.5 \times 10^{2}$ & 40 & + & $>400 \mathrm{~K}$ & + \\
\hline Intermediate & $\begin{array}{l}\text { Tribes } \\
\text { Chiefdoms }\end{array}$ & $1.2 \times 10^{3}$ & $\rightarrow 100$ & +++ & $10 \mathrm{~K}$ & ++ \\
\hline Large & $\begin{array}{l}\text { Nation states } \\
\text { Union of states }\end{array}$ & $\begin{array}{l}1 \times 10^{6-7} \\
1 \times 10^{8-9}\end{array}$ & $20-30$ & & $\begin{array}{l}0.5 \mathrm{~K} \\
0.03 \mathrm{~K}\end{array}$ & +++ \\
\hline
\end{tabular}

adapted from references 60, 66, and 69.

as the possession of special skills, knowledge, and resources. Consequently, the fraction of kin in "Dunbar's circle" also varies. Among hunter-gatherers, $40 \%$ of group members were kin in 1 study. In larger, more modern societies, kin comprise approximately $20 \%$ of the "circle of trust" [61]. The lower fraction of kin in developed nations is consistent with the previously discussed findings of higher trust of nonkin in richer societies and an associated higher productivity of nonkin social contracts (Table 1).

\section{The Changing Size of Human Groups: Agrarian}

Revolution and Emergence of Kinship Groups

Group size is important for human breeding because it affects the size of the pool (i.e., genetic diversity) of potential mates. Until about 10,000 years ago, human beings lived as hunter-gatherers in small groups of around 150 inhabitants. In such small groups, inbreeding was controlled by between-group migration. In many areas of the world, this population structure started to change in response to increases in fertility rate and population size resulting from the agricultural revolution. Population growth intensified competition for limited resources, thus increasing conflict between groups [62-64]. The outcomes of these conflicts were usually determined by group size as, historically, larger groups prevailed [6567].

The first step toward group enlargement was from small bands of hunter-gatherers to kinship groups. Male hunter-gatherers tended to join other groups upon reaching sexual maturity, a behavior that reduces inbreeding and is analogous to dispersal in animals [14]. In an environment of increased conflict, the relative value of each male increases the offensive and defensive power of the group. Military analysis has shown that strength is derived from numbers and that a linear increase in the num- ber of combatants results in an exponential increase in power, especially in mano a mano style of combat likely practiced in tribal wars [68]. Emigration of males thus ceased to be advantageous and stopped. This necessitated a change in the social norms governing the movement of group members[69]. When a son stays with his biological father (and other members of his nuclear family), they are more likely to sacrifice for each other and are expected to defend the family with more determination, vigor, and strength than would a biologically unrelated father-inlaw and son-in-law [18]. This combat advantage is the main reason for patrilocal family structures in $80 \%$ of societies worldwide [70-72].

The movement of women was also prohibited because, in interwar periods, they could be even more important for a group's long-term survival. In patrilocal societies, a woman moves after marriage to her husband's house and their children become members of the father's household. If a woman marries a man from another group, her offspring contribute to the size and power of another group, which, in the future, could be in conflict with her parents' group. The reproductive capacity of women (not men) is a rate-limiting factor in the growth of human populations. Thus, altruism and differences in the physical and reproductive biology of men and women shaped the structure and size of human families and communities.

In 1 study, tribe size varied between 500 and 2,000, with a mean of 1,155 [60]. In 1971, when the United Arab Emirates was formed, the mean size of tribal groups (estimated from a population of 800,000 with 65 tribes and subtribes) was 1,237 [72]. By banning outmigration from small bands of hunter-gatherers $(n=150)$, the size of kinship groups (tribes) increased nearly tenfold (Table 1).

Another way a kinship group could increase its numbers and strength was by allowing outsiders to join. People move from other groups for various reasons, for ex- 
ample, defection, breakup of a group, slavery, and political marriages. Such immigrants must gain trust before becoming accepted members of the tribe. Indeed, over generations, many nonkin have managed to gain trust and even become group leaders causing the "confusion of lineages" [73]. This method of group enlargement increases gene flow and counters the effects of inbreeding in small, isolated groups.

\section{Mean Coefficient of Relation in Kinship Groups and \\ Inner Strength (Asabiyya)}

Per the theory of altruism, the mean $R$ of a tribe determines the potential maximum sacrifice an average individual in a tribe is willing to make for the benefit of others. $R$ values in consanguineous families are higher, and the solidarity within kinship groups (compared to an equally sized group of biologically unrelated individuals) is expected to be higher. Indeed, in the 14th century, Ibn Khaldun attributed the invincibility of certain Arab tribes to their exceptional asabiyya (inner cohesion) [73]. In wartime, a higher mean $R$ value could act as a proxy for strength and fearlessness, theoretically increasing the odds of victory if there is an asymmetry between the relative fitness costs and benefits in a particular conflict. Likewise, in peacetime, a higher mean $R$ value could determine the success of business deals and accumulation of group wealth. Generalizing this pattern, the strength of kinship groups $(S)$ can be defined as $S=R \times N$, where $N$ is the group size.

The mean $R$ value of a kinship group is inversely related to its size and age. As the group size increases with each generation, the strength of kinship connections decreases because of biological limits on human memory. Without the help of a written record, no society exists wherein people know each second cousin once removed. Therefore, the second cousin once removed could be the "first" and the "safe-to-marry" nonkin. Indeed, the marriage of second cousins once removed is permitted in the vast majority of societies [3]. As mentioned, kinship (i.e., trust) is enlarged by extending feelings of fraternity to biologically unrelated individuals using cognitive abilities. This may include the use of family names, various means of signaling recognition to each other, accepting a single leader of the group, and judging kinship from an individual's proximity in time and space. In summary, kinship groups (tribes) comprise both kin and nonkin, and their strength is determined by their size and inner cohesion. Inner cohesion is directly related to human altruism (trust) and inversely related to group size. Human altruism is constrained partly by our inherited cognitive abilities and partly by our unique individual and communal experiences.
Conflict within the Group: Individual Well-Being versus Group Well-Being

The requirement for young adults to remain in the group entails that they also marry within the group. In fact, this marital norm exists in all tribal societies and is an absolute requirement for tribalism, that is, formation of kinship groups. Such social norms are contracts into which each and every individual enters the group by default at the time of birth. Social norms increase group strength, while violating them weakens the group. Consequently, defectors from social norms are punished to deter similar behavior by other group members [74].

Individuals select mates to maximize fitness; however, mate choice in kinship groups is constrained by small group size. As the size of a group decreases linearly, the pool of potential mates decreases in size exponentially [75]. Many additional factors define mate availability, for example, sex and age, marital status, physical and mental health, beauty, personality traits, family reputation, biological closeness, and incest taboo [16, 21]. Nonetheless, when mates are in short supply, the selection of close kin for a spouse is often the best reproductive option. One factor that counteracts such a choice is human aversion to inbreeding. However, this could be allayed by measures to increase the "physical" distance between close kin of the opposite sex. Thus, starting at a certain age in Arab countries, children of opposite sex are separated in play, prayer, and dress code. This may reduce parent-offspring conflict in mate selection and has been shown not to affect the fertility of consanguineous couples [76].

In general, an unsanctioned union with a member of another group is considered illegal or invalid and is broken by group members. Defectors may be punished through disinheritance, withdrawal of family and communal support, and sometimes murder (honor killings) [77]. In tribal societies, remarriage after a dishonorable divorce and without family support is impossible and is tantamount to inability to reproduce, that is, total loss of fitness $[1,8,10]$. The purpose of punishment is to discourage others, and experimental studies have shown it to increase group strength effectively [74, 78]. In summary, close-kin marriages are a compromise between the biological interests of the individual (fitter offspring) and that of society (higher survival).

\section{Increasing Trust, Making Alliances, and Escaping from Poverty}

Another way a group may increase in size is through an alliance with another group. Historically, this was perhaps the most important means by which human groups grew 
in size (Table 1) $[66,79]$. An alliance is a social contract between the leaders of 2 or more groups. As a bigger group, an alliance is more likely to win a conflict, thus increasing trust between the original groups. This self-reinforcing characteristic of alliances increases the odds of maintaining cooperation. Initially, however, the formation of an alliance requires the willingness of leaders (and group members) to jeopardize their well-being by trusting others. Among tribal populations characterized by widespread mistrust of nonkin, this proposition may be difficult to accept. Nonetheless, at least 2 historical factors have facilitated increases in altruism and creation of alliances: intergroup (political) marriages and availability of natural resources.

Intergroup marriages are arranged between the offspring of leading families and are usually considered taboo for other families. The creation of a blood bond increases trust, which passes along the 2 family trees to other members of the groups. The success of such an alliance further builds trust, increasing the odds of its survival. Thus, the initial blood bond $(R)$ works as a catalyst to build altruism between members of the 2 groups and strengthen their connections $(R u)$.

Human altruism can increase with the availability of natural resources. The abundance of resources lowers the intensity of competition and the odds of conflict. In Africa and Arabian Peninsula, abundance of rain and oil wealth have lowered tribal conflicts and stimulated group alliances, respectively [80]. In general, the availability of recourses in the form of favorable geography and climate is positively correlated with the size and wealth of human groups $[81,82]$.

\section{The Relationship between Marriage Patterns and} Altruism

Marriage is a social contract with many benefits. A breach of its terms can be costly, particularly for women who invest more in offspring and in traditional societies wherein family support is more important. In 1 study in Pakistan, tribal women indicated that a high risk of maltreatment by members of a biologically unrelated husband's family was the main reason for marrying within the family [31]. They avoid outbreeding because of the lack of trust. This is particularly significant as women are generally more averse to inbreeding compared with men $[15,25,26]$. Conversely, in socioeconomically prosperous and more trusting societies, the number of inter-racial marriages (outbreeding) has increased steadily over the years [83-85]. The above examples indicate that human trust (altruism) is positively correlated with outbreeding and vice versa, that is, the lack of trust is associated with inbreeding. The latter is also associated with socioeconomic underdevelopment and poverty. Therefore, current social theories of consanguinity confound socioeconomic deprivation with human consanguinity.

\section{Conclusion}

The effect of close-kin marriages on relative fitness depends on the availability of marriageable nonkin - a shortage increases fitness, while an excess decreases it. Marriageable mates are scarce in small and isolated human groups; thus, a substantial amount of consanguinity in the world occurs in populations in geographical isolates and kinship groups within tribal societies. The reason for kin marriages among the former is easy to understand (geographic barriers) but is harder to explain in the latter. In tribal societies, the roots of consanguinity lie in the lack of altruism, which is a universal sociobiological principle of behavior. Altruism implies trust, which is essential for cooperation and socioeconomic development. When mistrust is widespread, people prudently avoid social contracts with nonkin and cooperate with the relatively more reliable kin. This ideological discrimination between kin and nonkin leads to a fragmentation of society into multiple kinship groups that are socially insulated from each other - akin to geographical isolates. In such populations, interactions are almost exclusively between kin. As these interactions are less far-reaching and productive than those with nonkin, overall socioeconomic development is diminished, thereby causing general economic hardship in tribal societies. Kinship groups also compete for limited resources and often fall into conflicts wherein bigger groups hold an advantage. To increase their strength in numbers, members are made to stay and marry within the group. Those who mate outside their group face sanctions for violating the community's marital norms - the interest of the group outweighs that of an individual. Kinship groups, being small, have fewer available marriageable mates who are biologically unrelated. To avoid remaining single and childless, many marry close kin. Such unions still produce many healthy offspring and thus present the best available reproductive option - individuals accept a fitness loss caused by inbreeding to avoid the complete loss of fitness incurred by not having any progeny. In short, a close-kin marriage is a compromise between the biological interests of an individual (fitter offspring) and that of society (higher survival). In environments lacking biologically unrelated mates, consanguinity often turns into an optimal mating strategy. 


\section{Conflict of Interest Statement}

The authors have no conflicts of interest to declare.

\section{Funding Sources} body.

This review paper received no specific grant from any funding

\section{References}

1 Bittles AH. The role and significance of consanguinity as a demographic variable. Popul Dev Rev. 1994;20(3):561-84.

2 Bittles AH, Black ML. Evolution in health and medicine Sackler colloquium: consanguinity, human evolution, and complex diseases. Proc Natl Acad Sci U S A. 2010;107(Suppl 1):177986. PubMed: 19805052

3 Bittles AH. Consanguinity in context. Cambridge: Cambridge University Press; 2012.

4 Wilson OE. Sociobiology: the new synthesis. Cambridge: Belknap Press; 1975.

5 Wilson OE. The social conquest of earth. New York: Liveright Publishing Co.; 2013.

6 Sapolsky MR. Behave: the biology of humans at our best and worst. New York: Penguin Press; 2017.

7 Levi-Strauss C. The elementary strucutes of kinship. Boston: Beacon Press; 1969.

8 Alwan A, Modell B. Community control of genetic and congenital disorders. Alexandria: Emro Technical Publications Series. WHO; 1997.

9 Jaber L, Halpern GJ, Shohat M. The impact of consanguinity worldwide. Community Genet. 1998;1(1):12-7. PubMed: 15178982.

10 Khlat M. Endogamy in the Arab world. In: Teebi AS, Farag TI, editors. Genetic disorders among Arab populations. New York: Oxford University Press; 1997. p. 63-80.

11 Bakoush O, Bredan A, Denic S. Kin and nonkin marriages and family structure in a rich tribal society. J Biosoc Sci. 2016;48(6):797805. PubMed: 26790338.

12 Kuper A. Incest, cousin marriage, and the origin of the human sciences in nineteenth-century England. Past Present. 2002;174(174): 158-83. PubMed: 20707037.

13 Duthie AB, Reid JM. What happens after in breeding avoidance? Inbreeding by rejected relatives and the inclusive fitness benefit of inbreeding avoidance. PLoS One. 2015;10(4) e0125140. PubMed: 25909185

14 Szulkin M, Stopher KV, Pemberton JM, Reid JM. Inbreeding avoidance, tolerance, or preference in animals? Trends Ecol Evol. 2013; 28(4):205-11. PubMed: 23182684.

15 Bakoush O, Nicholls MG, Denic S. Selection of kin for spouse: importance of socioeconomic status, reputation and beauty. J King Saud Univ Sci. 2016;28(4):286-92.

\section{Author Contributions}

The main idea was formulated by Srdjan Denic and modified by Mukesh Agarwal. Both authors participated in writing and editing of the manuscript.
16 Buss DM, Schmitt DP. Mate preferences and their behavioral manifestations. Annu Rev Psychol. 2019;70:77-110. PubMed: 30230999.

17 Clark G, Cummins N, Hao Y, Vidal DD. The son also rises: surnames and the history of social mobility. NJ, USA: Princeton University Press; 2014

18 Denic S, Nagelkerke N, Agarwal MM. Choice of kin in consanguineous marriages: effects of altruism and ecological factors. Ann Hum Biol. 2010;37(6):738-53. PubMed: 20367322.

19 Buss DM. Sex differences in human mate preferences: evolutionary hypotheses tested in 37 cultures. Behav Brain Sci. 1989;12(1): $1-14$.

20 Buss DM, Abbott M, Angleitner A, Asherian A, Biaggio A, Blanco-Villasenor A, et al. International preferences in selecting mates: a study of 37 cultures. J Cross Cultural Psychol. 1990;21(1):5-47.

21 Geary DC, Vigil J, Byrd-Craven J. Evolution of human mate choice. J Sex Res. 2004;41(1): 27-42. PubMed: 15216422.

22 Apostolou M. Individual mate choice in an arranged marriage context: evidence from the standard cross-cultural sample. Evol Psychol Sci. 2017;3(3):193-200.

23 Haig D. Asymmetric relations. Evol Hum Behav. 1999;20(2):83-98.

24 Lieberman D, Tooby J, Cosmides L. Does morality have a biological basis? An empirical test of the factors governing moral sentiments relating to incest. Proc Biol Sci. 2003; 270(1517):819-26. PubMed: 12737660.

25 Manson JH, Perry SE. Inbreeding avoidance in rhesus macaques: whose choice? Am J Phys Anthropol. 1993;90(3):335-44. PubMed: 8460656.

26 Trivers R. Parental investment and sexual selection. In: Campbell B, editors. Sexual selection and the descent of man, 1871-1971. Chicago: Aldine-Atherton; 1972. p. 136-79.

27 Apostolou M. Sexual selection under parental choice: evidence from sixteen historical societies. Evol Psychol. 2012;10(3):504-18. PubMed: 22947674.

28 Haig D. Parental antagonism, relatedness asymmetries, and genomic imprinting. Proc Biol Sci. 1997;264(1388):1657-62. PubMed 9404029.

29 Trivers RL. Parent-offspring conflict. Am Zool. 1974;14(1):249-64.
30 Milinski M. Reputation, a universal currency for human social interactions. Philos Trans R Soc Lond B Biol Sci. 2016;371(1687): 20150100.

31 Hussain R. Community perceptions of reasons for preference for consanguineous marriages in Pakistan. J Biosoc Sci. 1999;31(4): 449-61. PubMed: 10581876.

32 Werner C, Edling C, Becker C, Kim E, Kleinbach R, Sartbay FE, et al. Bride kidnapping in post-Soviet Eurasia: a roundtable discussion. Cent Asian Surv. 2018;37(4):582-601.

33 Hamilton WD. The genetical evolution of social behaviour. II. J Theor Biol. 1964;7(1):1752.

34 Hamilton WD. The genetical evolution of social behaviour. II. J Theor Biol. 1964;7(1):1752. PubMed: 5875340

35 Keller FL, Waller MD. Inbreeding effects in wild populations. Trends Ecol Evol. 2002;17: 19-23.

36 Denic S, Nagelkerke N, Agarwal MM. On some novel aspects of consanguineous marriages. Public Health Genomics. 2011;14(3): 162-8. PubMed: 21150168.

37 Gaissmaier W, Gigerenzer G. Statistical illiteracy undermines informed shared decision making. Z Evid Fortbild Qual Gesundhwes. 2008;102(7):411-3.

38 Turnpenny DP, Ellard S. Emery's elements of medical genetics. Philadelphia, PA: Elsevier; 2017.

39 Nowak MA, Highfield R. Super cooperators: altruism, evolution, and why we need each other to succeed. New York: Free Press; 2010.

40 Fehr E, Fischbacher U. The nature of human altruism. Nature. 2003;425(6960):785-91. PubMed: 14574401.

41 Nowak MA, Sigmund K. Evolution of indirect reciprocity. Nature. 2005;437(7063):1291-8. PubMed: 16251955.

42 Queller DC. Expanded social fitness and Hamilton's rule for kin, kith, and kind. Proc Natl Acad Sci U S A. 2011;108(Suppl 2): 10792-9. PubMed: 21690389.

43 Trivers RL. The evolution of reciprocal altruism. Q Rev Biol. 1971;46(1):35-57.

44 Dawkins R. The selfish Gene. Oxford: Oxford University Press; 1989.

45 Dunbar RIM. The social brain: mind, language, and society in evolutionary perspective. Annu Rev Anthropol. 2003;32(1):163-81. 
46 Nowak MA, Sigmund K. Evolution of indirect reciprocity by image scoring. Nature. 1998; 393(6685):573-7. PubMed: 9634232.

47 Nave G, Camerer C, McCullough M. Does oxytocin increase trust in humans. A critical review of research? Perspect Psychol Sci. 2015;10(6):772-89.

48 Lieberman D, Tooby J, Cosmides L. The architecture of human kin detection. Nature. 2007;445(7129):727-31. PubMed: 17301784.

49 Wolf AP. Childhood association and sexual attraction: a further test of the Westermarck hypothesis. Am Anthropol. 1970;72(3):50315.

50 Fletcher JA, Zwick M. Unifying the theories of inclusive fitness and reciprocal altruism. Am Nat. 2006; 168(2):252-62. PubMed: 16874634

51 Haig D. Genomic imprinting and the evolutionary psychology of human kinship. Proc Natl Acad Sci U S A. 2011;108 Suppl 2(Suppl 2):10878-85. PubMed: 21690414.

52 Oates K, Wilson M. Nominal kinship cues facilitate altruism. Proc Biol Sci. 2002 269(1487):105-9. PubMed: 11798424

53 FeldmanHall O, Dunsmoor JE, Tompary A, Hunter LE, Todorov A, Phelps EA. Stimulus generalization as a mechanism for learning to trust. Proc Natl Acad Sci U S A. 2018;115(7): E1690-7. PubMed: 29378964.

54 Jiang X, Sanford R, Pell MD. Neural architecture underlying person perception from ingroup and out-group voices. Neuro Image. 2018;181:582-97. PubMed: 30031933.

55 Zak PJ, Knack S. Trust and growth. Econ J. 2001;111(470):295-321.

56 Ortiz-Ospina E. Trust and GDP; 2016. Available from: https://ourworldindata.org/trustand-gdp. Accessed 2019 Jan 28.

57 Havlicek J, Roberts SC. MHC-correlated mate choice in humans: a review. Psychoneuroendocrinology. 2009;34(4):497-512. PubMed: 19054623

58 Bressan P, Kramer P. Human kin detection. Wiley Interdiscip Rev Cogn Sci. 2015;6(3): 299-311. PubMed: 26263231.

59 Dunbar RIM. Neocortex size as a constraint on group size in primates. J Hum Evol. 1992; 22(6):469-93.
60 Dunbar RIM. Coevolution of neocortical size, group size and language in humans. Behav Brain Sci. 1993;16(4):681-94.

61 Hill RA, Dunbar RI. Social network size in humans. Hum Nat. 2003;14(1):53-72. PubMed: 26189988.

62 North DC, Thomas RP. The first economic revolution. Econ Hist Rev. 1977;30(2):229_ 41.

63 Weisdorf JL. From foraging to farming: explaining the neolithic revolution. J Econ Surv. 2005;19(14):561-86.

64 Pinker S. The better angels of our nature: why violence has declined. New York: Viking Press Books; 2011.

65 Glowacki L, Wrangham R. Warfare and reproductive success in a tribal population. Proc Natl Acad Sci U S A. 2015;112(2):34853. PubMed: 25548190.

66 Turchin P. Ultrasociety: how 10,000 years of war made humans the greatest cooperators on earth. Chaplin, CT: Beresta Books; 2015.

67 Turchin P. Historical dynamics: why states rise and fall. Princeton, NJ: Princeton University Press; 2018.

68 Lanchester FW. Mathematics in warfare. In: Newman JR, editors. The world of mathematics. New York: Simon and Schuster; 1956. p. 2138-57.

69 Hill KR, Walker RS, Bozicević M, Eder J, Headland T, Hewlett B, et al. Co-residence patterns in hunter-gatherer societies show unique human social structure. Science. 2011; 331(6022):1286-9. PubMed: 21393537.

70 Murdock GP. World ethnographic sample. Am Anthropol. 1957;59(4):664-87.

71 van den Berghe PL, Barash DP. Inclusive fitness and human family structure. Am Anthropol. 1977;79(4):809-23.

72 Heard-Bey F. The tribal society of the UAE and its traditional economy. In: Al Abed I, Hellyer P, editors. United Arab Emirates: a new perspective. London: Trident Press Ltd; 2001. p. 98-116.

73 Khaldun I. The muqaddimah: an introduction of history. Princeton: Princeton University Press; 1958.
74 Fehr E, Fischbacher U, Gächter S. Strong reciprocity, human cooperation, and the enforcement of social norms. Hum Nat. 2002; 13(1):1-25. PubMed: 26192593.

75 Denic S, Agarwal MM, Nagelkerke N. Growth of consanguineous populations: effect of family and group size. Asian Pac J Trop Dis. 2012; 2:S227-32.

76 Bittles AH, Grant JC, Sullivan SG, Hussain R. Does inbreeding lead to decreased human fertility? Ann Hum Biol. 2002;29(2):111-30 PubMed: 11874619.

77 Thrasher J, Handfield T. Honor and violence: an account of feuds, duels, and honor killings. Hum Nat. 2018;29(4):371-89. PubMed: 30251000.

78 Mathew S, Boyd R. Punishment sustains large-scale cooperation in prestate warfare. Proc Natl Acad Sci U S A. 2011;108(28): 11375-80. PubMed: 21670285.

79 Turchin P, Gavrilets S. Evolution of complex hierarchical societies. Soc Evol Hist. 2009;8: 167-98.

80 Bruch C, Jensen D, Nakayama M, Unruh J. Human conflict: targeting natural resources. Science. 2012;337(6092):291-2. PubMed 22822132.

81 Diamond J. Guns, germs, and steel: the fates of huam societies. New York: WW Norton \& Co. Inc; 1972.

82 Hibbs DA, Olsson O. Geography, biogeography, and why some countries are rich and others are poor. Proc Natl Acad Sci U S A. 2004; 101(10):3715-20. PubMed: 14985502.

83 Livingston G, Brown A. Intermarriage in the U.S. 50 years after loving v. Virginia: 2017. Available from: http://www.pewsocialtrends. org/2017/05/18/intermarriage-in-the-u-s50-years-after-loving-v-virginia/. Accessed 2018 Jan 30.

84 Monahan TP. An overview of statistics on interracial marriage in the United States, with data on its extent from 1963-1970. J Marriage Fam. 1976;38(2):223-31.

85 Song M. Is intermarriage a good indicator of integration? J Ethn Migr Stud. 2009;35(2) $331-48$. 